\title{
Cerebellar gray matter explains bimanual coordination performance in children and older adults
}

Citation for published version (APA):

Boisgontier, M. P., Cheval, B., van Ruitenbeek, P., Cuypers, K., Leunissen, I., Sunaert, S., Meesen, R., Zivari Adab, H., Renaud, O., \& Swinnen, S. P. (2018). Cerebellar gray matter explains bimanual coordination performance in children and older adults. Neurobiology of Aging, 65, 109-120. https://doi.org/10.1016/j.neurobiolaging.2018.01.016

Document status and date:

Published: 01/05/2018

DOI:

10.1016/j.neurobiolaging.2018.01.016

Document Version:

Publisher's PDF, also known as Version of record

Document license:

Taverne

Please check the document version of this publication:

- A submitted manuscript is the version of the article upon submission and before peer-review. There can be important differences between the submitted version and the official published version of record.

People interested in the research are advised to contact the author for the final version of the publication, or visit the DOI to the publisher's website.

- The final author version and the galley proof are versions of the publication after peer review.

- The final published version features the final layout of the paper including the volume, issue and page numbers.

Link to publication

\footnotetext{
General rights rights.

- You may freely distribute the URL identifying the publication in the public portal. please follow below link for the End User Agreement:

www.umlib.nl/taverne-license

Take down policy

If you believe that this document breaches copyright please contact us at:

repository@maastrichtuniversity.nl

providing details and we will investigate your claim.
}

Copyright and moral rights for the publications made accessible in the public portal are retained by the authors and/or other copyright owners and it is a condition of accessing publications that users recognise and abide by the legal requirements associated with these

- Users may download and print one copy of any publication from the public portal for the purpose of private study or research.

- You may not further distribute the material or use it for any profit-making activity or commercial gain

If the publication is distributed under the terms of Article $25 \mathrm{fa}$ of the Dutch Copyright Act, indicated by the "Taverne" license above, 


\title{
Cerebellar gray matter explains bimanual coordination performance in children and older adults
}

\author{
Matthieu P. Boisgontier ${ }^{\mathrm{a}, \mathrm{b}, *}$, Boris Cheval ${ }^{\mathrm{c}, \mathrm{d}}$, Peter van Ruitenbeek ${ }^{\mathrm{a}, \mathrm{e}}$, Koen Cuypers ${ }^{\mathrm{a}}$, \\ Inge Leunissen ${ }^{\mathrm{a}}$, Stefan Sunaert ${ }^{\mathrm{f}}$, Raf Meesen ${ }^{\mathrm{g}}$, Hamed Zivari Adab ${ }^{\mathrm{a}}$, Olivier Renaud ${ }^{\mathrm{h}}$, \\ Stephan P. Swinnen ${ }^{\mathrm{a}, \mathrm{i}}$

\footnotetext{
${ }^{a}$ KU Leuven, Department of Movement Sciences, Movement Control and Neuroplasticity Research Group, Leuven, Belgium

${ }^{\mathrm{b}}$ Department of Physical Therapy, Brain Behavior Laboratory, University of British Columbia, Vancouver, Canada

${ }^{c}$ Department of General Internal Medicine, Rehabilitation and Geriatrics, University of Geneva, Geneva, Switzerland

' ${ }^{\mathrm{d}}$ Swiss NCCR “LIVES - Overcoming Vulnerability: Life Course Perspectives", University of Geneva, Geneva, Switzerland

e Department of Clinical Psychological Science, Faculty of Psychology and Neuroscience, Maastricht University, Maastricht, The Netherlands

${ }^{\mathrm{f}}$ KU Leuven, Translational MRI Unit, Department of Imaging and Pathology, Leuven, Belgium

${ }^{\mathrm{g}}$ REVAL Rehabilitation Research Center, Biomedical Research Institute, Faculty of Medicine and Life Sciences, Hasselt University, Leuven, Belgium

${ }^{\mathrm{h}}$ Methodology and Data Analysis Research Group, Faculty of Psychology and Educational Sciences (FAPSE), University of Geneva, Geneva, Switzerland

${ }^{\mathrm{i}}$ KU Leuven, Leuven Research Institute for Neuroscience \& Disease (LIND), Leuven, Belgium
}

\section{A R T I C L E I N F O}

\section{Article history:}

Received 26 June 2017

Received in revised form 12 January 2018

Accepted 21 January 2018

Available online 2 February 2018

\section{Keywords:}

Adolescent development

Aging

Brain

Internal model

Magnetic resonance imaging

Movement

\begin{abstract}
A B S T R A C T
The cerebellum appears to undergo late maturation in children and early decline at older age. Whether these age-related changes affect bimanual coordination performance remains unclear at best. Here, we identified the ages at which bimanual coordination performance stops improving and starts declining. In an independent cohort, we defined brain regions of interest involved in bimanual coordination using functional magnetic resonance imaging. We used these regions of interest to investigate the extent to which the gray matter of cerebellar and other brain regions explains bimanual coordination performance from 10- to 80 -year-olds. Results showed that bimanual coordination performance starts declining from the age of 40 years. In participants aged $10-20$ years, cerebellar lobule VI was the only significant brain predictor of bimanual coordination performance. In participants aged 60-80 years, this cerebellar region, together with the primary sensorimotor cortex, formed a group of strongest predictors. These results from 2 independent samples (10-20 and 60-80 years) suggest that cerebellar lobule VI is critical for the development and preservation of bimanual coordination skills in children and older adults, respectively. In addition, post hoc analyses suggested that the primary motor cortex mediated the adverse effect of age on bimanual coordination performance in older adults.
\end{abstract}

(c) 2018 Elsevier Inc. All rights reserved.

\section{Introduction}

Human aging is characterized by a progressive loss of physiological integrity that initiates shortly after development ceases (Sobel, 1966). From a movement control perspective, this agerelated loss of integrity can impact musculoskeletal receptors and effectors (Kararizou et al., 2005; Nair, 2005), and the nervous system processing, transmitting, and integrating sensorimotor information (e.g., brain gray and white matters; Fjell et al., 2013; Sexton et al., 2014). At older age, the adverse effects of cellular and tissue

\footnotetext{
* Corresponding author at: Brain Behavior Laboratory, Department of Physical Therapy, University of British Columbia, Vancouver, BC, Canada. Tel.: +1 604827 3369; fax: +16048221870.

E-mail address: matthieu.boisgontier@kuleuven.be (M.P. Boisgontier).
}

aging become behaviorally observable, but the age at which sensorimotor functions start declining varies. For example, muscle strength decline starts around age 30-40 years (Brooks and Faulkner, 1994; Kallman et al., 1990), whereas quiet standing balance (Abrahamová and Hlavacka, 2008) and fine unimanual movement performance (Smith et al., 1999) have been reported to start declining at age 60 years. However, the age at which bimanual movement performance starts declining remains unclear.

In everyday functioning, bimanual movements occur twice as often as unimanual movements (Rinehart et al., 2009; VegaGonzalez and Granat, 2005) and they serve as a critical marker of functional independence (Katz et al., 1970). This calls for a better understanding of how bimanual performance changes over the lifespan. Performance on bimanual coordination tasks depends on the brain's ability to effectively integrate sensorimotor information 
(Swinnen, 2002). Many studies have investigated the extent to which aging impacts the relationship between bimanual coordination performance and brain function and/or structure (for a review, see Maes et al., 2017). In children, the microstructural organization of the corpus callosum, the largest white matter bundle in the brain, correlates with performance on alternated bimanual finger tapping (Marion et al., 2003; Muetzel et al., 2008). However, it remains unclear which gray matter structures best determine bimanual coordination performance at this age. In adults, the brain areas associated with bimanual coordination include, among others, the primary sensorimotor areas (Donchin et al., 1998; Puttemans et al., 2005), supplementary motor area (SMA; Puttemans et al., 2005; Sadato et al., 1997; Swinnen and Wenderoth, 2004), premotor cortex (Sadato et al., 1997; Swinnen and Wenderoth, 2004), prefrontal cortex (Puttemans et al., 2005), motor cingulate (Puttemans et al., 2005), basal ganglia (putamen, globus pallidus, caudate, and nucleus accumbens; Chalavi et al., 2018; Puttemans et al., 2005), and cerebellum (Swinnen and Wenderoth, 2004; Tracy et al., 2001), with prominent activity in the latter region (Debaere et al., 2004a). In older adults aged 61-78 years, activity during a bimanual coordination task increases as compared to younger adults aged 21-31 years in cortical areas, such as the SMA, dorsolateral prefrontal cortex, parietal cortex, secondary somatosensory area, and cingulate cortex (Goble et al., 2010). Moreover, gray matter volume of the primary motor cortex (M1), primary somatosensory cortex (S1), premotor cortex, motor cingulate, and SMA has been shown to be positively associated with bimanual coordination performance in task-related cortical areas (van Ruitenbeek et al., 2017). However, it remains unknown which of these brain regions best explains bimanual performance across the lifespan.

The cerebellum is a good candidate as it has been repeatedly reported as being significantly associated with task performance (Beets et al., 2015; Debaere et al., 2003, 2004a,b; Goble et al., 2010; Santos Monteiro et al., 2017; Wenderoth et al., 2004, 2006). Moreover, we recently suggested that the cerebellum could be critical for determining the impact of aging on motor control in adults, due to early cerebellar neuron death (Boisgontier, 2015). The cerebellum is divided into 10 vermal and hemispheric lobules organized in lobes: the anterior lobe (lobules $I-V$ ), posterior lobe (lobules VI-IX), and flocculonodular lobe (lobule X) (Schmahmann et al., 2000). These lobules are each related to motor and cognitive functions (Stoodley and Schmahmann, 2010; Stoodley et al., 2012). Extracerebellar structures involved in sensorimotor processing are anatomically linked with the anterior lobe (lobules II-V) and lobule VIII (Kelly and Strick, 2003; Snider and Eldred, 1951; Stoodley and Schmahmann, 2009), and hand sensorimotor representation is located in lobules V and VIII (Grodd et al., 2001). Extracerebellar structures involved in nonmotor processing are anatomically linked to lobules VI and VII (Stoodley and Schmahmann, 2010). However, some sensorimotor tasks also rely on spatial representation and executive functions that involve the cerebellar posterior lobe (Donchin et al., 2012; Rabe et al., 2009). Populations of neurons in the cerebrum and cerebellum are not equally affected by normal aging. The number of neurons is stable in many cerebral areas (Peters and Kemper, 2012), whereas the anterior lobe of the cerebellum undergoes a $40 \%$ loss of both Purkinje and granule cells (Andersen et al., 2003), which typically starts at the age of 50-60 years (Hall et al., 1975). This loss is concurrent with a volume decline (Luft et al., 1999; Walhovd et al., 2005) in almost all lobules (Bernard and Seidler, 2013b). This difference in neuron loss between the cerebrum and cerebellum can be explained by the agerelated vulnerability of cerebellar neurons. Specifically, Purkinje cells show high and premature susceptibility to mitochondrial and proteostasis defects (Hekman and Gomez, 2015), whereas cerebellar granule cells are particularly vulnerable to oxidative stress (Wang and Michaelis, 2010). Because the cerebellum estimates intrinsic and extrinsic forces that act on the body (Huang et al., 2013; Laurens et al., 2013; Wolpert et al., 1998), this early neuron loss may prevent the cerebellum from outputting accurate force estimates, thereby increasing the computational load required to perform a motor task at the same level as in younger adults (Boisgontier et al., 2013). At the cortical level, this additional load is indicated by age-related hyperactivation, which has been reported in regions involved in bimanual coordination (Coxon et al., 2010; Goble et al., 2010). At the behavioral level, the additional computational load is indicated by a declining ability to perform a motor task concurrently with another task (Verhaeghen et al., 2003). These inaccurate estimates also likely result in an increased reliance on reactive motor control, which is based on time-delayed sensory feedback. Due to such delays, movement corrections are always late with regard to the portion of movement they intend to correct. Accordingly, individuals with inaccurate estimates are expected to reach their goal through a series of corrective movements. This increased number of corrective movements has consistently been reported in children and older adults compared to younger adults (e.g., Boisgontier and Nougier, 2013; Burton, 1987; Helsen et al., 2016; Yan et al., 2000). At the other end of the age range, the cerebellum shows protracted development (Wang and Zoghbi, 2001), with volume peaking at the age of 11-16 years (Tiemeier et al., 2010). Behavioral studies using smooth pursuit eye movements or split-belt walking have suggested late maturation of predictive mechanisms in children (Ego et al., 2016; Vasudevan et al., 2011), which may be linked to the protracted development. Taken together, these results suggest that the cerebellum is critical for sensorimotor functions early and late in the lifespan.

We tested the ages at which bimanual coordination performance stopped improving and started declining. We also investigated the extent to which the gray matter structure of brain regions of interest (ROIs) involved in bimanual coordination explained performance in participants aged from 10 to 80 years. We hypothesized that, compared to other ROIs involved in bimanual coordination, the cerebellar ROI is a stronger predictor of performance, particularly in children and older adults. To further investigate which parts of the cerebellum are the most critical for bimanual coordination over the lifespan, we used a voxelwise approach over the whole cerebellum (Diedrichsen, 2006; Diedrichsen et al., 2009). We hypothesized that the anterior lobe and lobule VI are strong predictors of bimanual coordination performance as they have been shown to be critical for motor tasks (i.e., sequence learning and visuomotor adaptation; Bernard and Seidler, 2013a) and specifically for bimanual coordination tasks (Debaere et al., 2004a). As studies showed that the anterior lobe (Andersen et al., 2003; Bernard and Seidler, 2013b) and vermis (Luft et al., 1999; Raz et al., 2001) were more impacted by age than other cerebellar regions, we also hypothesized that the gray matter volume of these structures explains more variance in bimanual coordination performance in older adults.

\section{Methods}

\subsection{Participants}

One hundred nine healthy volunteers (age range 10-80 years; mean age $44 \pm 21$ years; $n=11-21$ per 10 -year age cohort) participated in the study. Based on the spline results (see section 3.1 ), the data set was split at 20 and 40 years. Given the known effect of aging, a split was added at 60 years. These splits resulted in 4 age groups: children and adolescents ( $\mathrm{n}=17 ; 10-20$ years), younger adults $(\mathrm{n}=32 ; 20-40$ years $)$, middle-aged adults $(\mathrm{n}=28$; 
$40-60$ years), and older adults ( $n=32 ; 60-80$ years). All participants were right-handed according to the Edinburgh Handedness Inventory (Oldfield, 1971). All participants had a normal or corrected-to-normal vision and no neurological, psychiatric, or cardiovascular disorders. All participants or their parents gave their written informed consent, and procedures were performed according to guidelines established by the ethics committee for biomedical research at KU Leuven, Belgium, and in accordance with the World Medical Association International Code of Medical Ethics.

\subsection{Experimental setup}

Participants were seated in front of a computer monitor with both forearms resting on a custom-made adjustable ramp. A 5-cm diameter dial was mounted at the end of each ramp. Angular displacements of the dials were registered by nonferromagnetic

A
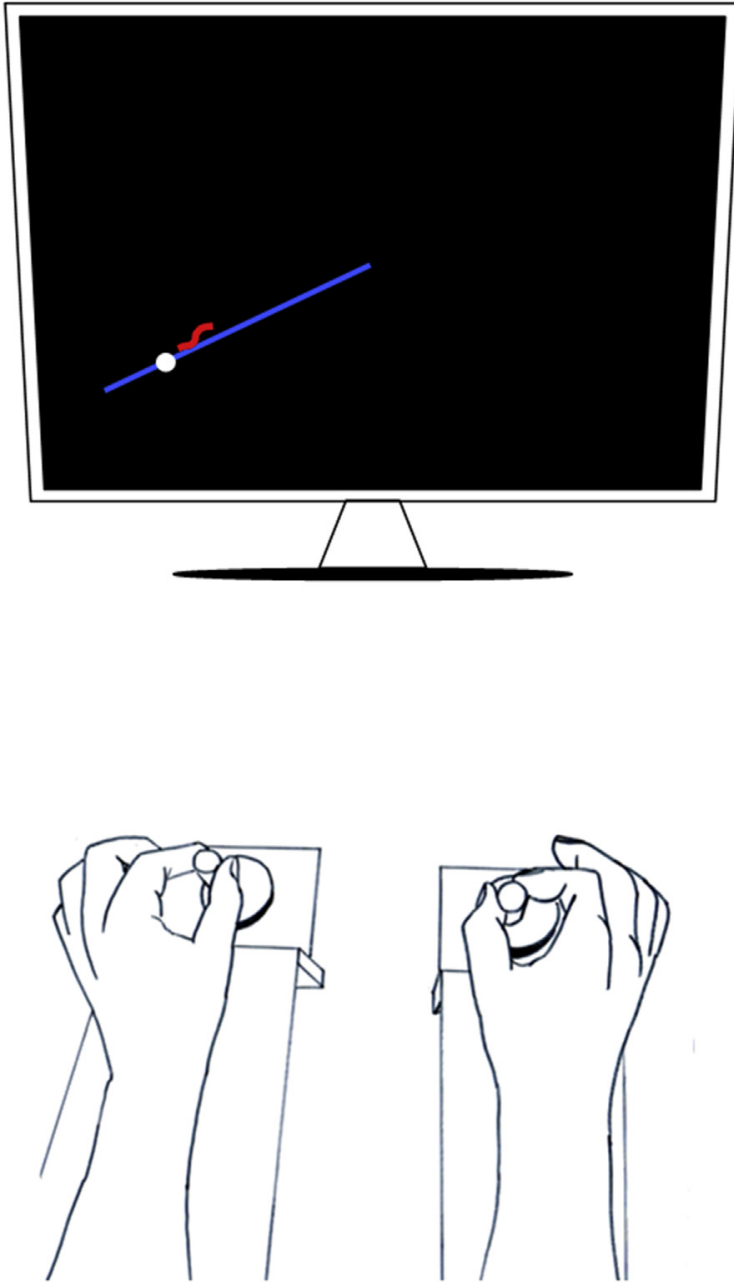

optical shaft encoders (Avago Technologies, sampling frequency $=100 \mathrm{~Hz}$, accuracy $=0.089^{\circ}$ ) fixed to the rotation axes of the dials. The gain was set to 10 arbitrary units (au) per rotation and 16.2 complete rotations of the left or right dial were required to draw a vertical or horizontal line of the same length as the experimental target lines on a computer screen.

\subsection{Bimanual multifrequency tracking task}

Participants were presented with a white target dot on a computer screen. They were instructed to track the dot as it moved along a blue line by rotating the dials with the thumb and index finger of both hands according to specific coordination patterns and frequency ratios without vision of the upper limbs. As they rotated the dials, a red cursor moved on the screen to provide online visual feedback (Fig. 1A). Four bimanual coordination patterns

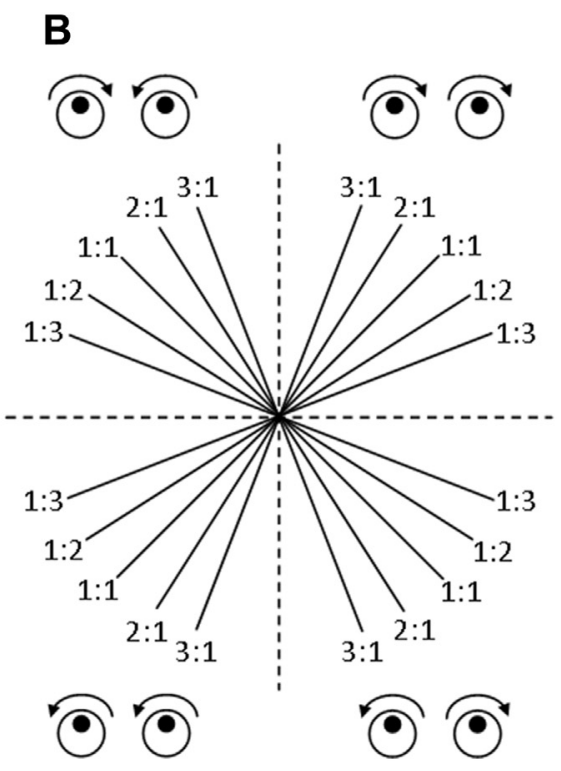

C

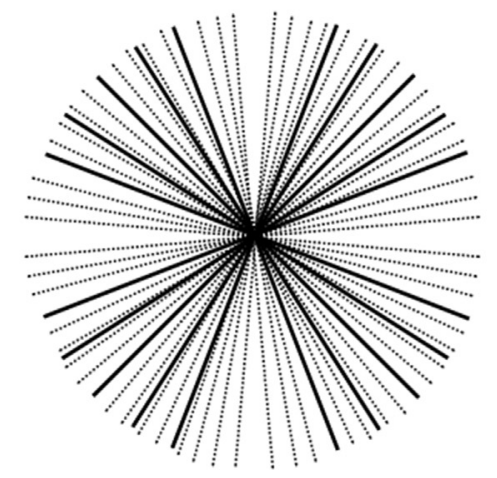

Tested conditions

Other potential bimanual conditions

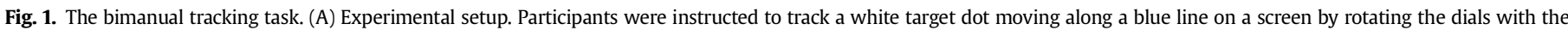

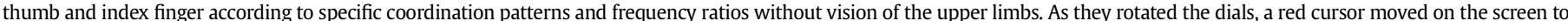

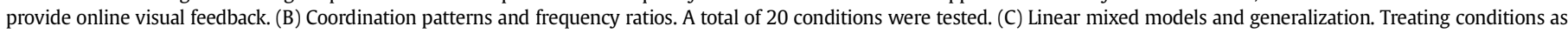

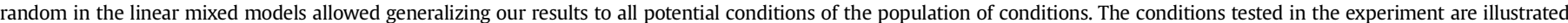

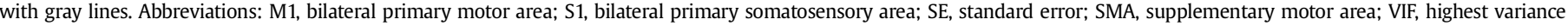
inflation factor. (For interpretation of the references to color in this figure legend, the reader is referred to the Web version of this article.) 
corresponding to the target line direction were tested: inward, outward, clockwise, and counter-clockwise hand rotation. The left and right hands controlled movements on the ordinate axis and abscissa axis, respectively. Each pattern was performed according to 5 frequency ratios: 1:1,1:2,1:3,2:1, and 3:1 (left hand:right hand), resulting in 20 different target line directions (Fig. 1B).

\subsection{Procedure}

Before data recording, participants performed 12 familiarization trials with different target lines to get used to the dial-cursor couples (left dial clockwise-cursor moves up; left dial counterclockwise-cursor moves down; right dial clockwise-cursor moves to the right; right dial counterclockwise-cursor moves to the left). These trials were performed without accuracy requirements and were not recorded. Before each recorded trial, the target line appeared for 2 seconds. The target dot then moved along the line for 10 seconds at a constant speed from the center of the screen to the end of the target line. The goal was to match the movement of the white dot (target) with the movement of the red feedback dot as accurately as possible in terms of both space and time. The intertrial interval was 3 seconds. Four 6-minute blocks with 3-minute rests in-between were administered, each consisting of 24 trials presented in a pseudorandom order. All participants performed a total of 96 recorded trials, for a total of 10,464 observations. Each block included all 20 distinctive target lines, with the 1:1 trial for each coordination pattern repeated twice.

\subsection{Physical activity}

Physical activity was assessed using the International Physical Activity Questionnaire (Booth, 2000), which assesses physical activity undertook across leisure time, domestic and gardening activities, and work-related and transport-related activities. The specific types of activity are classified into 3 categories: walking, moderate-intensity activities, and vigorous-intensity activities. Frequency (days per week) and duration (time per day) are collected separately for each specific activity category. The total score used to describe physical activity was computed as the weighted sum of the duration (in minutes) and frequency (in days) of walking, moderate-intensity, and vigorous-intensity activities. Each type of activity was weighted by its energy requirements defined in metabolic equivalent of task (MET): 3.3 METs for walking, 4.0 METs for moderate physical activity, and 8.0 METs for vigorous physical activity (Ainsworth et al., 2000). The total score of the International Physical Activity Questionnaire has been shown to correlate with objective measures of physical activity such as maximal treadmill time (Papathanasiou et al., 2010), accelerometer data (Craig et al., 2003; Mäder et al., 2006), pedometer data (Deng et al., 2008), and actimeter data (Scheeres et al., 2009).

\subsection{Kinematic data analysis}

Accuracy was assessed by the target deviation of the time series, computed as follows for each trial:

Target deviation $=\sum_{1}^{n} \sqrt{\left(x_{\text {cursor }}-x_{\text {target }}\right)^{2}+\left(y_{\text {cursor }}-y_{\text {target }}\right)^{2}}$

where $\mathrm{n}$ is the number of data samples over a trial of $10 \mathrm{~s}\left(10 \times 10^{2}\right)$, $x_{\text {cursor }}$ and $y_{\text {cursor }}$ are the respective position of the red cursor on the $\mathrm{x}$ and $\mathrm{y}$ axes, and $x_{\text {target }}$ and $y_{\text {target }}$ are the respective position of the white target dot on the $\mathrm{x}$ and $\mathrm{y}$ axes. Higher target deviation scores reflected poorer performance.

\subsection{Structural brain imaging}

\subsubsection{Image acquisition}

Brain images were acquired on a 3.0 T Siemens Magnetom Trio magnetic resonance imaging scanner (Siemens, Erlangen, DE) with a 12-channel head coil. For all participants, a high-resolution T1weighted structural image was acquired using magnetizationprepared rapid gradient-echo imaging (repetition time, $2.3 \mathrm{sec}$ onds; echo time, $2.98 \mathrm{~ms}$; flip angle, $9^{\circ} ; 160$ slices; voxel resolution, $1.0 \times 1.0 \times 1.1 \mathrm{~mm}$; field of view, $240 \times 256 \mathrm{~mm}$ ).

\subsubsection{Image processing for the comparison of cerebellar versus other ROIS}

All T1 structural images were manually checked for the presence of anatomical abnormalities and magnetic resonance artifacts. Cortical gray matter structure was analyzed using optimized voxelbased morphometry (VBM; Good et al., 2001; Smith et al., 2004; Douaud et al., 2007). This morphometric method estimates gray matter volume based on high-resolution three-dimensional magnetic resonance images. The VBM procedure involves the spatial normalization of the images from all the participants into the same stereotaxic space, segmentation of the gray matter from the spatially normalized images, and smoothing of these gray matter segments, which transforms volume differences into image intensity differences (Ashburner and Friston, 2000). Gray matter volume was our primary gray matter measure of interest. Structural images were brain-extracted, centered on the massa intermedia, gray matter segmented, and subsequently registered to the MNI152 standard space using nonlinear registration (Andersson et al., 2007). Images were then averaged to create a gray matter template for each age group: children and adolescents (10-20 years), younger adults (20-40 years), middle-aged adults ( $40-60$ years), older adults (60-80 years), and middle-aged and older adults (40-80 years). All native images for each group were nonlinearly registered to this group-specific template and modulated to correct for local vertex expansion or atrophy. Modulated images were then smoothed with an isotropic Gaussian kernel with a sigma of $4 \mathrm{~mm}$. Total intracranial volume was then calculated using VBM8 in SPM8 (Ridgway et al., 2011).

To determine the ROIs for analysis, we used a separate activation map based on a task-related functional magnetic resonance imaging (fMRI) data set from our laboratory. The data set comprised functional images of 26 younger (aged 17-27 years; Beets et al., 2015) and 25 older adults (aged 60-80 years; Chalavi et al., 2018; Santos Monteiro et al., 2017) who did not participate in the present study but who performed a similar task. Individual bloodoxygen-level-dependent contrasts of interest were created based on the difference between activity during a bimanual coordination task and in a control condition without movement (Beets et al., 2015). A conjunction analysis [younger (bimanual task $>$ baseline) $\cap$ older adults (bimanual task $>$ baseline)] of z-score maps was performed to obtain overlapping regions between younger and older adults (Nichols et al., 2005). Significance was set at $p<0.05$, with familywise error (FWE) correction for multiple comparisons and brain activity clusters larger than 20 voxels. The resulting functional map represents the brain areas that are active during bimanual coordination in both younger and older adults. To define ROIs for our VBM analysis, we used the regions from the statistical map of the conjunction analysis with peak voxel at z-score $\geq 4.20$ (van Ruitenbeek et al., 2017), which corresponded to $p$-values < $1 \times 10^{-4}$ after correction for FWE. These ROIs are consistent with the ROIs of another study investigating the brain regions involved in the control of bimanual coordination in younger and older adults (Goble et al., 2010). The resulting 9 ROIs are illustrated in Fig. 2 and detailed in Supplemental Table 1: the bilateral M1, bilateral S1, 
bilateral SMA, bilateral premotor cortex (dorsal and ventral), right middle frontal gyrus, bilateral superior parietal cortex, bilateral inferior occipital cortex, cerebellar lobule VI (vermis and hemispheres), and motor cingulate. These ROIs were binarized and used to extract the mean intensity of the gray matter voxels in each ROI for each participant, using the fslmeants command.

The ROI approach was implemented to test the extent to which subregions of the cerebellum explained bimanual coordination performance as compared to other brain ROIs. This approach allowed the application of linear mixed models (also known as hierarchical models; see section 2.8.2) that have shown to provide a better framework than traditional regression analyses (Boisgontier and Cheval, 2016). The ROI approach was complemented by a whole-cerebellum voxelwise analysis.

\subsection{Statistical analysis}

\subsubsection{Nonparametric local smoothing: spline analysis}

The effect of age on bimanual coordination performance over the lifespan is expected to be nonlinear (Leinen et al., 2016; Fig. 3A) and is generally modeled with the inclusion of a quadratic or cubic term in the equation. However, this approach presents several limitations (Davidian and Giltinan, 1995), and nonparametric local smoothing has been shown to be more robust (Fjell et al., 2010). The spline smoothing method is described in detail in Hastie et al.
(2008) and Wood (2006). Using the R language mgcv package, version 1.8-12 (http://www.r-project.org/), we implemented smoothing splines to define age ranges for which the age effect was linear. Because splines have not yet been developed to determine significance in designs such as that used in the present study, we used linear mixed models to test which brain regions involved in bimanual coordination were the best predictors of performance.

\subsubsection{Linear mixed models}

The extent to which the 9 ROIs explained the normalized target deviation for each independent age group was analyzed using linear mixed models. For each group, we built a data set with repeated nested measurements crossed with each condition to create linear mixed models with crossed random factors. Unlike traditional analysis of variance, linear mixed models take into account both the nested (multiple observations within a single participant in a particular condition) and crossed (participants observed in multiple conditions) structure of the data, thereby providing results with lower type I error rates, that is, stronger reliability (Baayen et al., 2008). In light of the recent concerns about false-positive rates in imaging studies (Eklund et al., 2016), the addition of such conservative statistical methods to imaging analyses should be promoted. Linear mixed models also avoid information loss due to averaging over trials (Judd et al., 2012). Moreover, as illustrated in Fig. 1C, treating both participants and

A
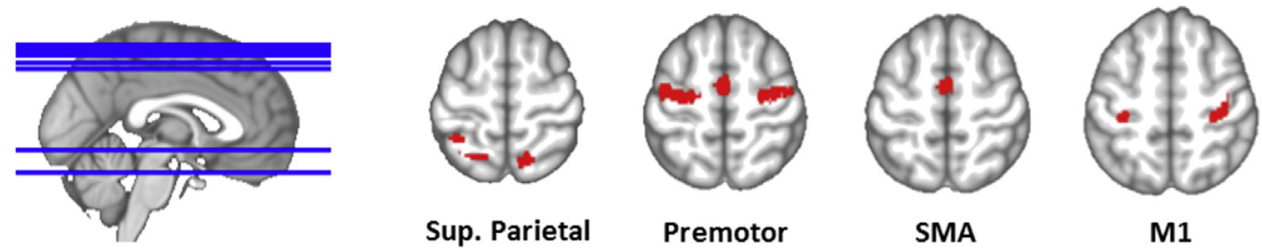

Sup. Parietal

Premotor

SMA

M1
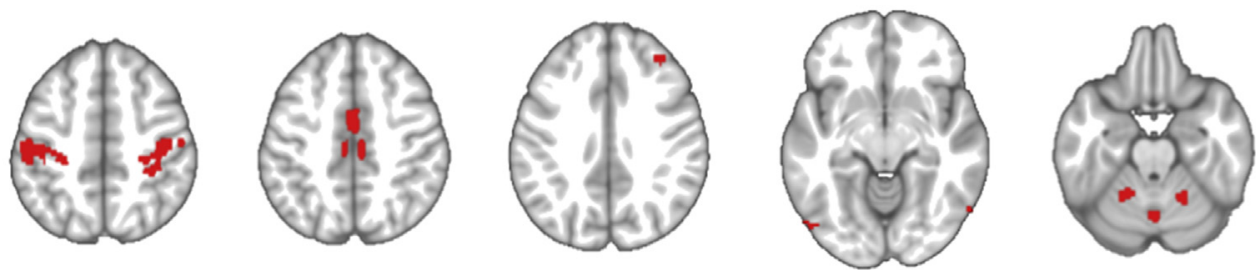

S1

Cingulate

Mid. Frontal

Inf. Occipital

Cerebellum

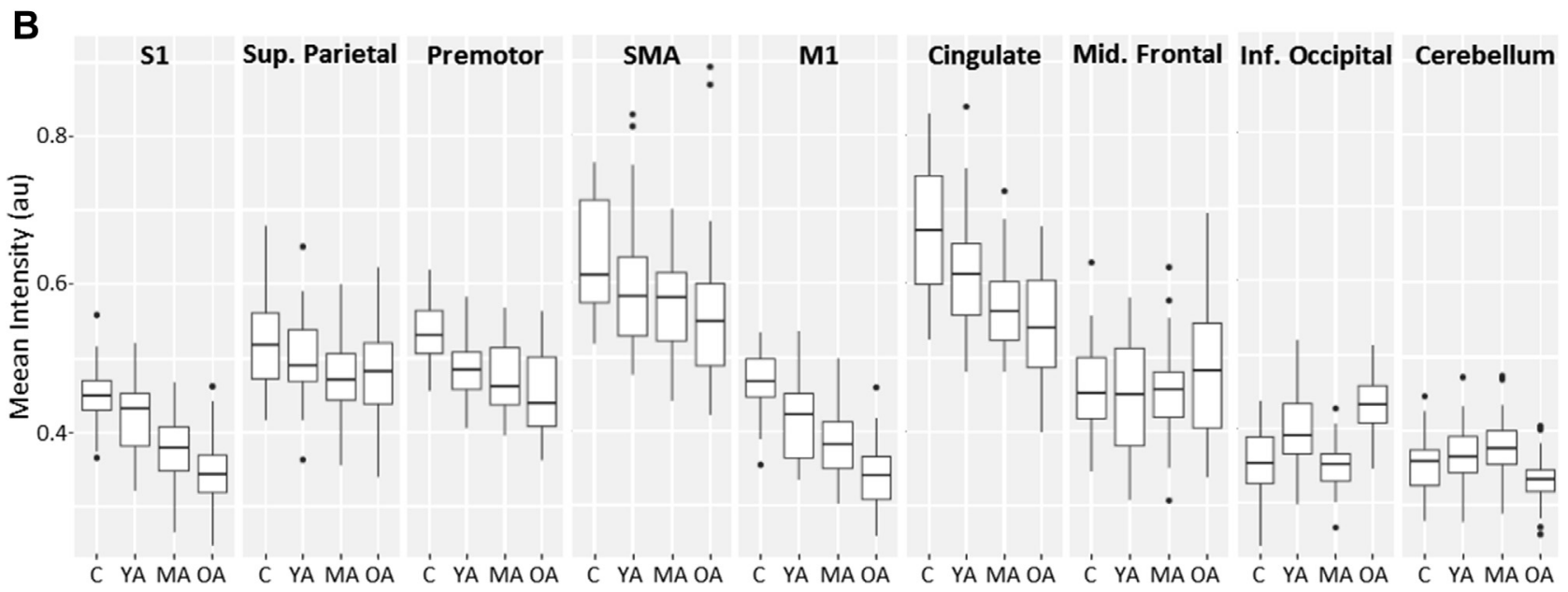

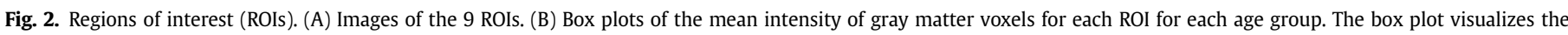

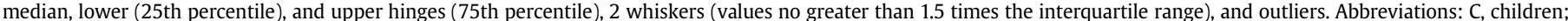

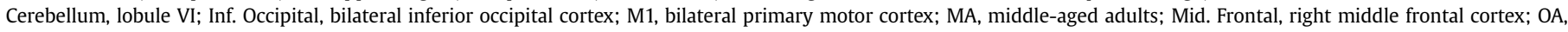
older adults; S1, bilateral primary somatosensory cortex; SMA, supplementary motor area; Sup. Parietal, superior parietal cortex; YA, younger adults. 


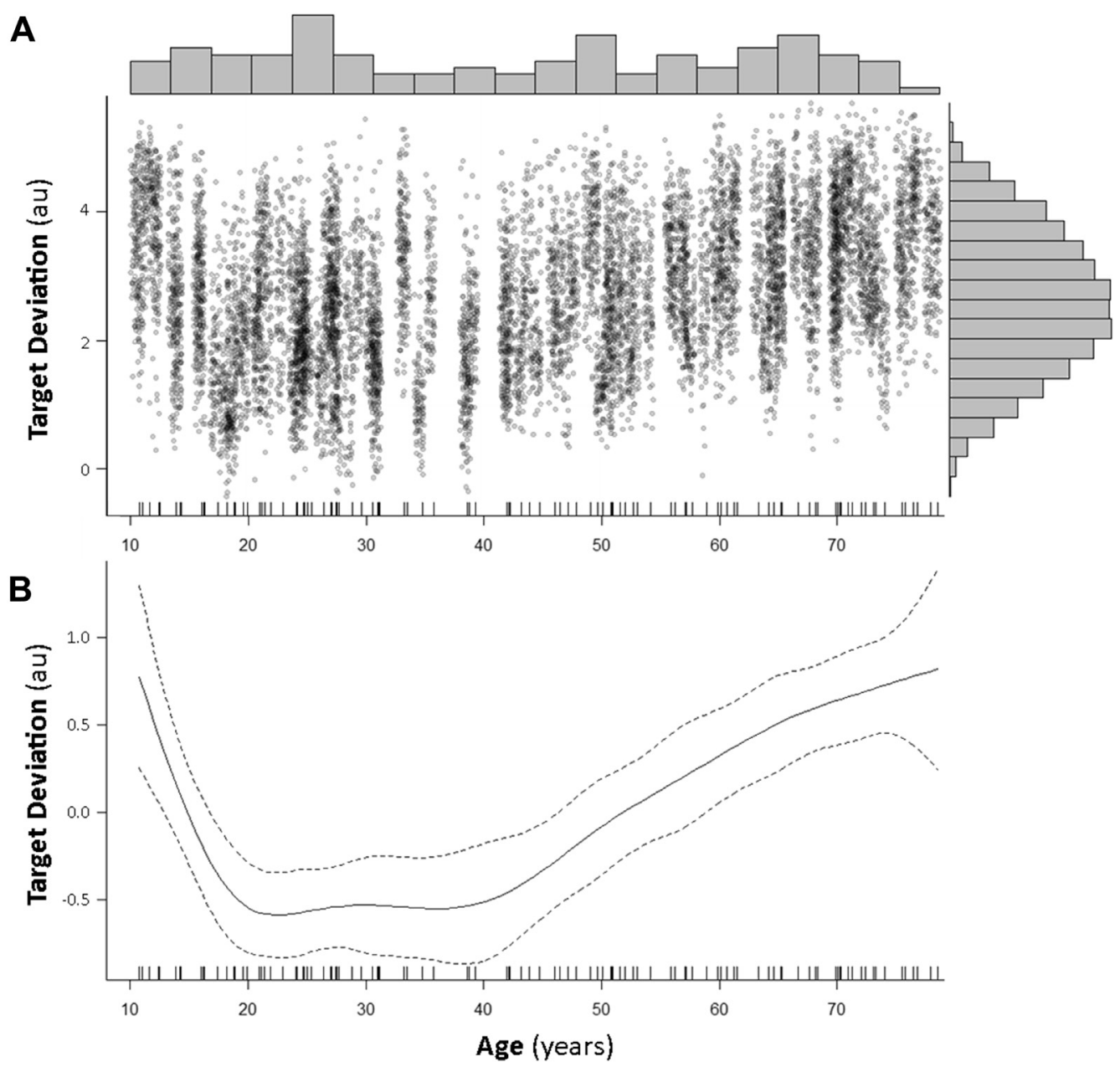

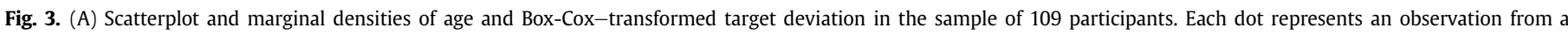

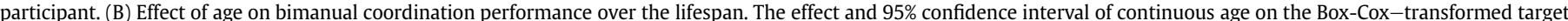

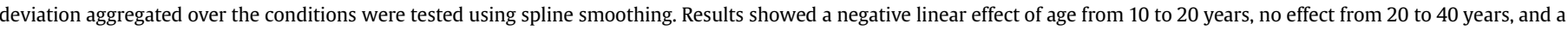
positive linear effect from 40 to 80 years.

conditions as random effects allows generalizing the results not only to the population of participants but also to the population of conditions (Barr et al., 2013). Linear mixed model series specifying participants and target condition $(n=20)$ as random factors were built for each age group using the $\mathrm{R}$ language lmerTest package, version 2.0-30 (http://www.r-project.org/). p-values were calculated based on Satterthwaite's approximations for degrees of freedom. All models were fitted using maximum likelihood to allow between-model comparisons within series (Faraway, 2006; Zuur et al., 2009) based on the Akaike Information Criterion, with lower scores indicating more accurate fit. In each model, target deviation was normalized using the Box-Cox method (Box and Cox, 1964; Osborne, 2010). The covariates were age, gender, physical activity, trial number, session number, and total intracranial volume. Physical activity was included in the models to control for its effect on bimanual coordination (Boisgontier et al., 2017b) and brain structure (Williams et al., 2017). Whether the significant effects of the ROIs were modulated by physical activity was also checked by including an interaction term in the equation, but this interaction was never significant (all $p$-values $>$ 0.05 ). The order of trials and sessions were included in the models to control for potential practice effects (i.e., fatigue and/or learning effects; Maes et al., 2017). Order of trials can be used as a control with linear mixed models only, as traditional analyses of variance require averaging trials. The continuous variables were standardized. For each group, an unconditional model and a conditional model including the control variables (Supplemental Table 2) were tested to provide a basis for pseudo $\mathrm{R}^{2}$ computation. The 9 ROIs were then included in the models (full model; Supplemental Table 2). The equation of the full models was as follows:

$$
\begin{aligned}
& \mathrm{Y}_{\mathrm{ij}}=\left(\beta_{0}+\gamma_{0 \mathrm{i}}+\theta_{0 \mathrm{j}}\right)+\beta_{1} \text { Continuous Age } \mathrm{j}_{\mathrm{j}}+\beta_{2} \text { Gender }_{\mathrm{j}} \\
& +\beta_{3} \text { Trial }_{\mathrm{ij}}+\beta_{4} \text { Session }_{\mathrm{ij}}+\beta_{5} \text { Physical Activity }_{\mathrm{j}} \\
& +\beta_{6} \text { Total Intracranial Volume }_{j}+\beta_{7} \text { Premotor }_{j} \\
& +\beta_{8} \text { Primary Somatosensory }_{\mathrm{j}}+\beta_{9} \text { Superior Parietal }_{\mathrm{j}} \\
& +\beta_{10} \text { Middle Frontal }_{j}+\beta_{11} \text { Inferior Occipital }_{j}
\end{aligned}
$$

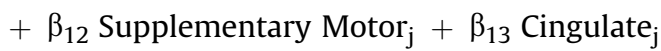

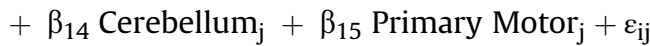

where $Y_{i j}$ is the participant's score in condition $\mathrm{i}, \beta_{0}$ to $\beta_{15}$ are the fixed effect coefficients, $\gamma_{0 i}$ is the random effect for condition $i$ (random intercept), $\theta_{0 \mathrm{j}}$ is the random effect for participant $\mathrm{j}$ (random intercept), and $\varepsilon_{\mathrm{ij}}$ is the error term.

In the first 3 models in the series (unconditional model, model with covariates, and full model), $p$-values were retrieved from the 
model fitted using maximum likelihood to minimize type 2 error rates (Luke, 2017). Finally, a sensitive model excluding the nonsignificant ROIs was tested, with $p$-values retrieved using restricted maximum likelihood to reduce type 1 error rates (Luke, 2017). The threshold for statistical significance was set to 0.05 . Beta estimates (b) above $0.20,0.30$, and 0.50 were indicative of small, medium, and large effect sizes, respectively (Cohen, 1988). Multicollinearity was quantified using variance inflation factors (VIFs), with lower scores indicating lower multicollinearity. A VIF score higher than 10 generally indicates high multicollinearity (e.g., Hair et al., 1995). Here, we reported the highest VIF across predictors. Pseudo $\mathrm{R}^{2}$ values were computed to estimate the percentage reduction of prediction errors from the unconditional to the conditional model. Pseudo $\mathrm{R}^{2}$ values are estimates of the effect sizes, such as $R^{2}$ values in traditional ordinary least squares regression analysis (Singer and Willett, 2003).

\subsubsection{Mediation analysis}

Using the $R$ language RMediation package (version 1.1.4) in Lavaan (version $0.5-20$ ), we performed a multiple mediation analysis to investigate the significant ROIs reported in older adults (M1, S1, and cerebellum) as potential mediators of the relationship between continuous age and target deviation in the different age groups. Participant's gender, physical activity, and total intracranial volume were also included in the model as control variables.

\subsection{Complementary analysis}

The ROI approach supported our hypothesis of a prominent role of the cerebellum as compared to other brain regions involved in the sensorimotor control of bimanual coordination (see section 3.2). To complement the ROI approach, we used a whole-cerebellum voxelwise approach to test voxels that were not included in the ROI approach (i.e., voxels that were not significantly activated during bimanual coordination performance in younger and older adults in the fMRI analysis; see section 2.7.2). As a first preprocessing step, the anatomical magnetic resonance imaging scan for each participant was segmented into gray matter, white matter, cerebrospinal fluid, skull, skin, and out-of-brain tissue using SPM8. To further optimize spatial normalization of the infratentorial structures, we used the SUIT toolbox v2.7 (http://www.diedrichsenlab.org/imaging/suit. htm; Diedrichsen, 2006; Diedrichsen et al., 2009). Gray mater segments were manually cropped in MRIcron (https://www.nitrc.org/ projects/mricron) to remove the brainstem and isolate the cerebellum. The cropped images were subsequently normalized to the SUIT template using the DARTEL engine (Ashburner, 2007) while correcting for volume changes due to normalization (i.e., affine modulation). The resulting normalization parameters were used to reslice the gray matter segments for each participant into SUIT atlas space. Global cerebellum volume was quantified by integrating the tissue probabilities over all voxels in the native segmented images. To avoid possible edge effects around the border between white and gray matters, we used an absolute gray matter threshold of $p<0.2$. To preserve precision in the definition of the cerebellum, a 4-mm default full width at half-maximum Gaussian kernel was used for smoothing. We applied an explicit brain mask to the gray matter segment to include only voxels that were considered as gray matter in $80 \%$ of all participants with a 0.2 probability. The association between the cerebellum volume and target deviation was tested using a multiple regression model with continuous age and total intracranial volume as covariates. Statistical inference was performed at the cluster level (cluster defining height threshold $p<0.001$ ), correcting for multiple comparisons over the search volume using FWE correction at $p<0.05$. Anatomical localization of the cerebellar lobules was determined using the probabilistic magnetic resonance imaging atlas of the human cerebellum (Diedrichsen et al., 2009).

\section{Results}

\subsection{Bimanual coordination performance over the lifespan}

Smoothing splines were used to robustly assess the effect of age on the normalized target deviation. Specifically, the effect of age on the Box-Cox-transformed target deviation, aggregated over the conditions, was tested with no other effect in the model. A cubic regression smoothing spline was used with 6.25 degrees of freedom estimated automatically by generalized cross-validation. Results showed a negative linear effect of age from 10 to 20 years, no effect from 20 to 40 years, and a positive linear effect from 40 to 80 years (Fig. 3B). No low-level polynomial could correctly approximate this effect over the entire age range.

\subsection{Cortical predictors of bimanual coordination performance by age group}

In the sensitive model for participants aged $10-20$ years $(n=17$; 11 females), the mean intensity of the gray matter voxels in the cerebellum ROI showed a significant fixed effect on target deviation ( $b=-0.368, p=0.022$; Table 1 ; Fig. 4 ), with higher intensity predicting lower target deviation. None of the other ROIs significantly explained target deviation. Control variables explained $84 \%$ of the variance in target deviation, with age $(b=-0.594, p=0.002)$, practice effect across sessions ( $b=-0.168, p<2 \times 10^{-16}$ ), and physical activity $(b=-0.294, p=0.041)$, each making a significant contribution to the regression equation. The addition of the 6 ROIs (inferior occipital cortex, SMA, premotor cortex, S1, M1, and cerebellum) to the model increased the explained variance by $11 \%$.

In the sensitive model for participants aged $20-40$ years $(n=32$; 17 females), none of the ROIs significantly explained target deviation (Table 1). Control variables explained $20 \%$ of the variance in target deviation, with practice effect across sessions $(b=-0.154, p<2 \times$ $10^{-16}$ ) making a significant contribution to the regression equation.

In the sensitive model for participants aged 40-60 years ( $\mathrm{n}=$ $28 ; 14$ females), the mean intensity of the gray matter voxels in the cingulate $(b=-0.210, p=0.041)$, premotor $(b=0.219, p=0.022)$, and S1 ROIs ( $b=0.275, p=0.005)$ showed a significant fixed effect on target deviation (Table 1; Fig. 4). Higher intensity in the cingulate ROI predicted lower target deviation, whereas higher intensity in the premotor and S1 ROIs predicted higher target deviation. Control variables explained $31 \%$ of the variance in target deviation, with age ( $b=0.173, p=0.035)$ and practice effect across sessions $\left(b=-0.118, p<2 \times 10^{-16}\right.$ ) each making a significant contribution to the regression equation. The addition of the 3 ROIs to the model increased the explained variance by $29 \%$.

In the sensitive model for participants aged $60-80$ years $(\mathrm{n}=$ $32 ; 14$ females), the mean intensity of the gray matter voxels in the S1 $(b=0.583, p=0.029)$, M1 $(b=-0.517, p=0.041)$, and cerebellum ROIs ( $b=-0.354, p=0.026$ ) showed a significant fixed effect on target deviation (Table 1; Fig. 4). Higher intensity in the M1 and cerebellum ROIs predicted lower target deviation, whereas higher intensity in the S1 ROI predicted higher target deviation. Control variables explained $42 \%$ of the variance in target deviation, with gender $\left(b=-0.916, p<7 \times 10^{-4}\right)$, practice effect across trials $(b=-0.006, p=0.016)$ and sessions $\left(b=-0.182, p<2 \times 10^{-16}\right)$, and physical activity $(b=0.308, p=0.012)$, but not age $(b=0.165$, $p=0.154$ ), making a significant contribution to the regression equation. The addition of the 3 ROIs to the model increased the explained variance by $18 \%$.

Given the similar performance slope for the 40-60 and 60-80 groups (Fig. 3), a complementary analysis was performed to investigate whether the significant effects of the ROIs in these 2 groups interacted with age. In this model ( $n=60 ; 28$ females), the 
Table 1

Cortical predictors of bimanual coordination performance over the lifespan

\begin{tabular}{|c|c|c|c|c|c|c|c|c|c|c|c|c|}
\hline \multirow[t]{2}{*}{ Fixed Effects } & \multicolumn{3}{|c|}{$\begin{array}{l}10-20 \text { y } \\
\text { Participants: } 17 \\
\text { Observations: } 1632 \\
\text { Conditions: } 20\end{array}$} & \multicolumn{3}{|c|}{$\begin{array}{l}20-40 \text { y } \\
\text { Participants: } 32 \\
\text { Observations: } 3072 \\
\text { Conditions: } 20\end{array}$} & \multicolumn{3}{|c|}{$\begin{array}{l}40-60 \text { y } \\
\text { Participants: } 28 \\
\text { Observations: } 2688 \\
\text { Conditions: } 20\end{array}$} & \multicolumn{3}{|c|}{$\begin{array}{l}60-80 \text { y } \\
\text { Participants: } 32 \\
\text { Observation: } 3072 \\
\text { Conditions: } 20\end{array}$} \\
\hline & $\mathrm{b}$ & SE & $p$ & $\mathrm{~b}$ & SE & $p$ & $\mathrm{~b}$ & SE & $p$ & $\mathrm{~b}$ & SE & $p$ \\
\hline Intercept & 3.035 & 0.108 & $<4 \times 10^{-10 * * *}$ & 2.444 & 0.152 & $<2 \times 10^{-14 * * *}$ & 2.881 & 0.112 & $<2 \times 10^{-16 * * *}$ & 5.094 & 0.163 & $<2 \times 10^{-16 * * *}$ \\
\hline Age & -0.594 & 0.072 & $0.002^{* *}$ & -0.113 & 0.085 & 0.260 & 0.173 & 0.065 & $0.035^{*}$ & 0.165 & 0.098 & 0.154 \\
\hline Gender & 0.021 & 0.167 & 0.941 & 0.022 & 0.252 & 0.940 & -0.221 & 0.157 & 0.244 & -0.916 & 0.202 & $<7 \times 10^{-4 * * *}$ \\
\hline Trial & ${ }^{-} 0.002$ & 0.003 & 0.537 & -0.001 & 0.002 & 0.705 & -0.002 & 0.002 & 0.237 & -0.006 & 0.003 & $0.016^{*}$ \\
\hline Session & ${ }^{-} 0.168$ & 0.016 & $<2 \times 10^{-16 * * *}$ & -0.154 & 0.009 & $<2 \times 10^{-16 * * *}$ & -0.118 & 0.011 & $<2 \times 10^{-16 * * *}$ & -0.182 & 0.016 & $<2 \times 10^{-16 * * *}$ \\
\hline Physical activity & ${ }^{-} 0.294$ & 0.069 & $0.041^{*}$ & -0.033 & 0.088 & 0.747 & 0.076 & 0.067 & 0.345 & 0.308 & 0.099 & $0.012^{*}$ \\
\hline TIV & -0.331 & 0.084 & 0.055 & -0.195 & 0.126 & 0.190 & 0.047 & 0.072 & 0.587 & 0.039 & 0.103 & 0.747 \\
\hline Inferior Occipital & ${ }^{-} \mathbf{0 . 1 7 6}$ & 0.066 & 0.159 & & & & & & & & & \\
\hline SMA & ${ }^{-} 0.256$ & 0.087 & 0.126 & -0.064 & 0.172 & 0.751 & & & & & & \\
\hline Cingulate & & & & -0.239 & 0.141 & 0.154 & -0.210 & 0.082 & $0.041^{*}$ & & & \\
\hline Premotor & 0.383 & 0.105 & 0.070 & 0.388 & 0.178 & 0.071 & 0.219 & 0.075 & $0.022^{*}$ & & & \\
\hline S1 & 0.319 & 0.095 & 0.089 & & & & 0.275 & 0.075 & $0.005^{* *}$ & 0.583 & 0.219 & 0.029* \\
\hline M1 & -0.359 & 0.102 & 0.077 & & & & & & & -0.517 & 0.209 & $0.041^{*}$ \\
\hline Cerebellum & -0.368 & 0.072 & $0.022^{*}$ & & & & & & & -0.354 & 0.130 & $0.026^{*}$ \\
\hline Random effects & $\sigma^{2}$ & & & $\sigma^{2}$ & & & $\overline{\sigma^{2}}$ & & & $\sigma^{2}$ & & \\
\hline Participant intercept & 0.034 & & & 0.194 & & & 0.095 & & & 0.189 & & \\
\hline Condition intercept & 0.065 & & & 0.039 & & & 0.032 & & & 0.090 & & \\
\hline Residual & 0.497 & & & 0.333 & & & 0.384 & & & 1.003 & & \\
\hline Pseudo $\mathrm{R}^{2}$ & & 0.953 & & & 0.352 & & & 0.598 & & & 0.600 & \\
\hline AIC & & & 3602.4 & & & 5551.8 & & & 5221.5 & & & 8899.3 \\
\hline VIF & & & 4.781 & & & 5.165 & & & 1.894 & & & 7.679 \\
\hline
\end{tabular}

The extent to which the bilateral primary motor area (M1), primary somatosensory area (S1), supplementary motor area (SMA), premotor cortex, right middle frontal, superior parietal cortex, inferior occipital cortex, cerebellum (lobule VI), and cingulate regions of interest (ROIs, in bold) were predictive of the normalized target deviation in each

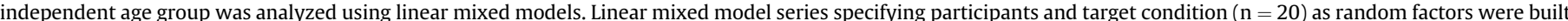

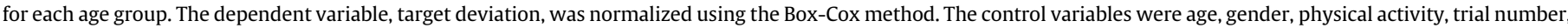

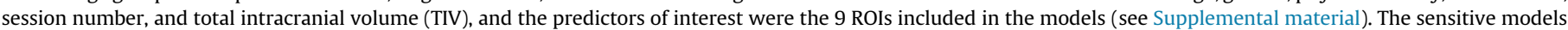

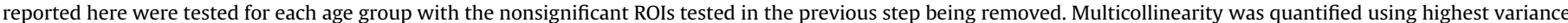

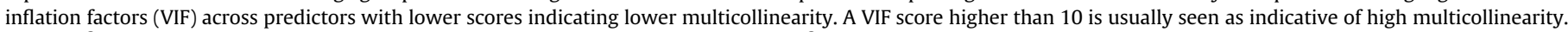

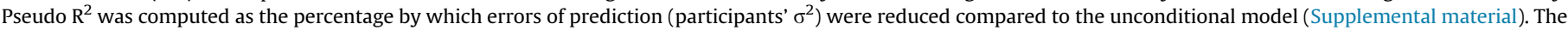
Akaike Information Criterion (AIC) was used as an indicator of fit accuracy, with lower scores indicating a more accurate fit.

Key: SE, standard error.

${ }^{*} p<0.05,{ }^{* *} p<0.01,{ }^{* * *} p<0.001$ retrieved using restricted maximum likelihood.

mean intensity of the gray matter voxels in the cerebellum $(b=-0.168, p=0.038)$, cingulate $(b=-0.186, p=0.024)$, and S1 ROIs $(b=0.425, p=0.002)$ still showed a significant fixed effect on target deviation. However, none of the ROIs interacted with age (all p's $>0.223$ ). This result suggests that future studies on the impact of the cerebellum on bimanual coordination in aging could start sampling at the age of 40 years to determine whether the mechanisms involved differ between these 2 age groups.

The complementary voxelwise analysis of the whole-cerebellum gray matter segment showed no significant effect.

\subsection{Primary motor cortex mediation}

In the sensitive model for participants aged 60-80 years, the nonsignificance of the fixed effect of age (Table 1 ) was inconsistent with the spline analysis (Fig. 3). In addition, this effect was significant when the ROIs were not included in the model (Supplemental Table 2D). Therefore, we used a multiple mediation model to investigate whether the positive relationship between continuous age of older adults and target deviation $(b=0.265, p=0.015$; Fig. $5 \mathrm{~A}$ ) was mediated by the mean intensity of gray matter voxels

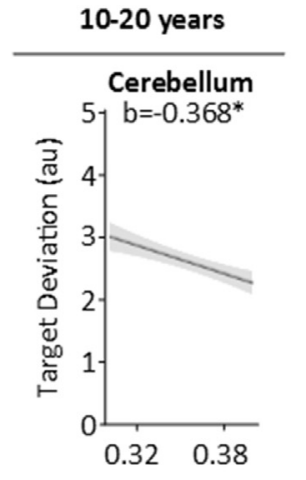

Mean intensity (au)
40-60 years

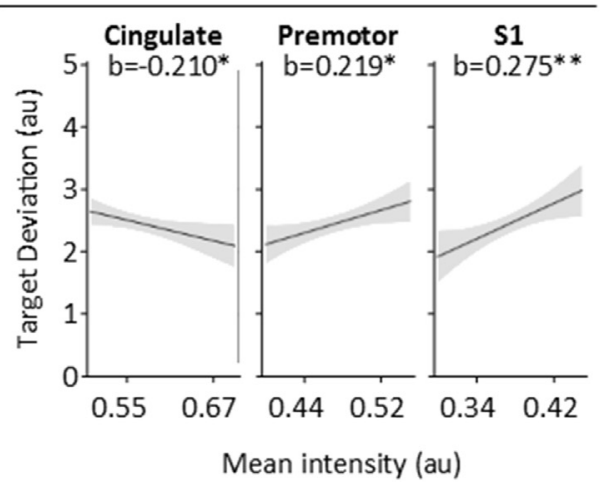

$60-80$ years

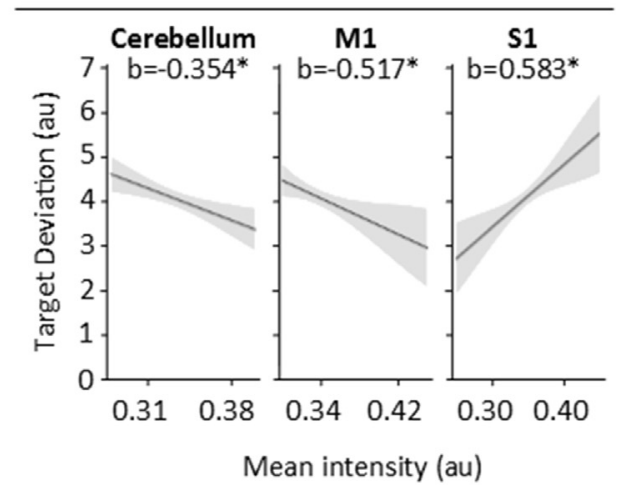

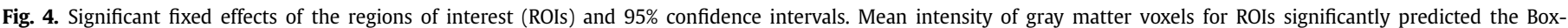

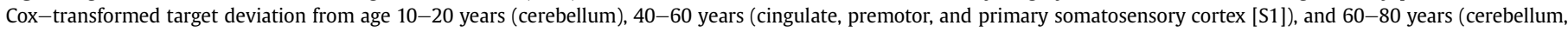
primary motor cortex [M1], and S1). ${ }^{*} p<0.05,{ }^{* *} p<0.01$. 
in the M1, cerebellum, and/or S1 ROIs. Results showed an indirect effect of M1 ( $b=0.252, p=0.032$; Fig. 5B), whereby the age-related lower intensity of this structure $(b=-0.488, p=0.001)$ predicted higher target deviation $(b=-0.527, p=0.004)$. The indirect effects of S1 $(b=-0.197, p=0.087)$ and the cerebellum $(b=0.044, p=$ 0.479) and the total indirect effect of the 3 ROIs ( $b=0.099, p=$ 0.154 ) were not significant. These results suggest that, in older adults, the age-related decrease in M1 volume may be indirectly responsible for the age-related increase in target deviation.

\section{Discussion}

In this study, we investigated whether the cerebellum was a stronger predictor of bimanual coordination performance than other ROIs in 109 participants aged 10-80 years. Results showed that bimanual coordination performance starts declining at age 40 years and that in participants aged $10-20$ years, the cerebellar ROI was the only significant brain predictor of bimanual coordination performance. In participants aged $60-80$ years, the cerebellar ROI also formed a group, together with the M1 and S1, of the strongest predictors. Moreover, the M1 mediated the adverse effect of age on bimanual coordination performance in older adults.

\subsection{Turning points in bimanual coordination performance over the lifespan}

Age-related improvement in bimanual accuracy in childhood and impairment in older adults have been widely demonstrated (e.g., Leinen et al., 2016; Maes et al., 2017; Marion et al., 2003) and were therefore expected here. However, the ages at which bimanual coordination performance stops improving and starts declining remained unclear. Using smoothing splines, we showed that bimanual coordination performance on a bimanual multifrequency tracking task stopped improving at age 20 years, which concurs with previous findings of a positive correlation between age and alternated finger tapping performance in children aged 9-24 years (Muetzel et al., 2008). Results also showed that performance declined from age 40 years or 20 years earlier than for fine unimanual movement performance (Smith et al., 1999). This earlier decline could be explained by the higher complexity of bimanual relative to unimanual tasks (Boisgontier et al., 2014), as this difference has been shown to determine the age effect on performance, with higher impact on older than younger adults (Moes et al., 1995). The reason for this difference may relate to compensatory mechanisms such as the ones defined in the compensation-related utilization of neural circuits hypothesis (Grady, 2012; Reuter-Lorenz and Cappell, 2008; Schneider-Garces et al., 2010). In less complex conditions, cognitive resources are still available and could be used to compensate for the age-related decline of the sensorimotor system. However, when the task becomes more complex, these compensatory mechanisms become more difficult to implement, which results in an impaired behavioral performance. The importance of cognitive resources, such as attention and working memory, in bimanual coordination tasks has been evidenced in children (Corporaal et al., 2017) and older adults (Goble et al., 2010).

\subsection{The cerebellum explains bimanual coordination performance early and late in life}

As hypothesized, gray matter structure of the cerebellar ROI (lobule VI) involved in bimanual coordination was a strong predictor of bimanual coordination performance in older adults, with higher intensity predicting higher performance. As the cerebellum

A
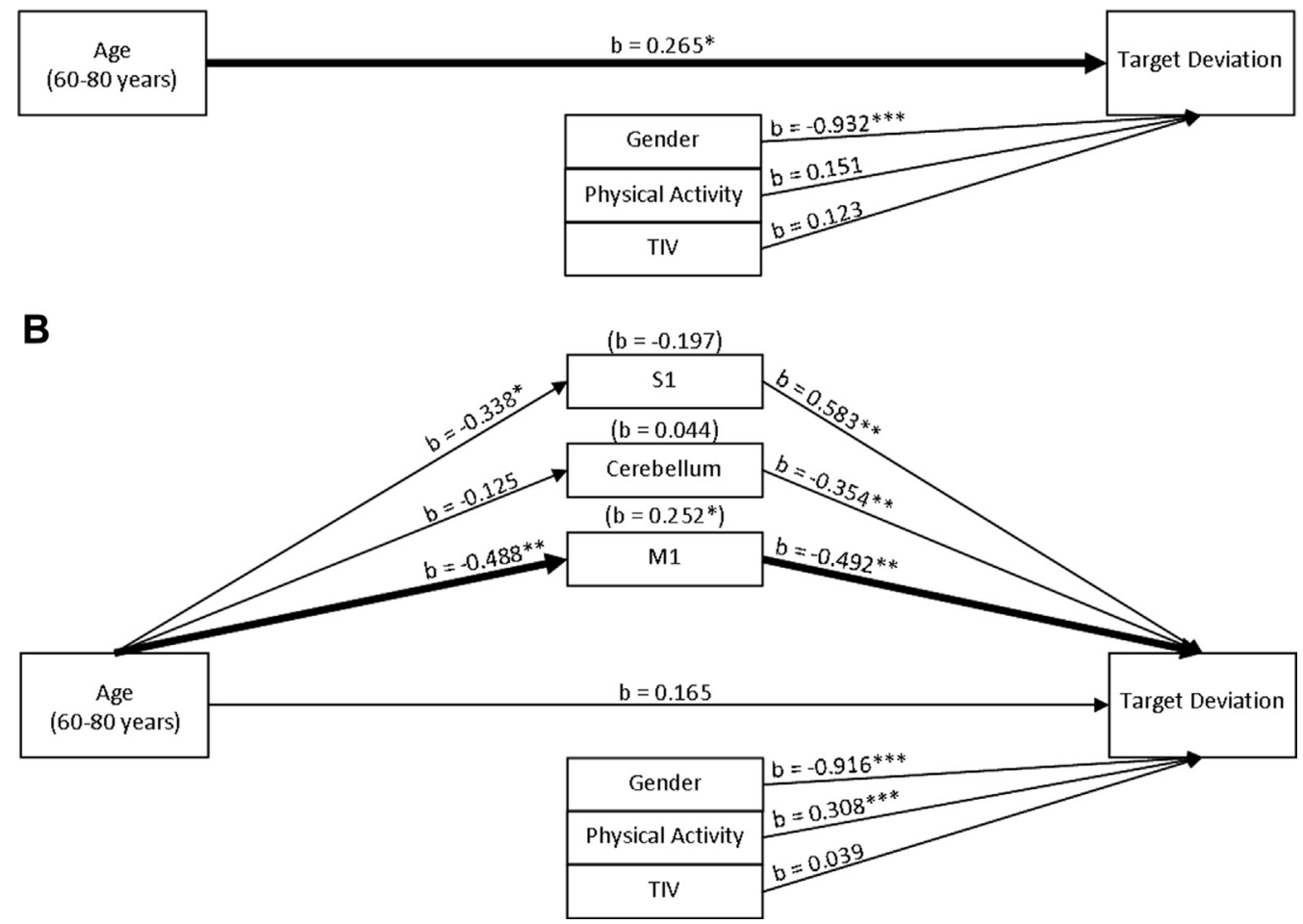

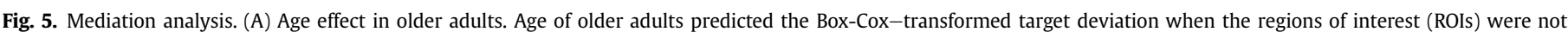

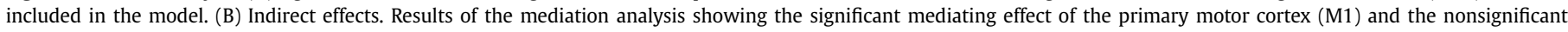
mediating effect of the primary somatosensory cortex (S1) and cerebellum. ${ }^{*} p<0.05,{ }^{* *} p<0.01,{ }^{* * *} p<0.001$. Abbreviation: TIV, total intracranial volume. 
has been shown to be critical for predictive movement control (Huang et al., 2013; Laurens et al., 2013; Wolpert et al., 1998), our results support previous studies suggesting age-related decline in this control mechanism (Boisgontier and Nougier, 2013; Casamento-Moran et al., 2017). These studies showed age-related differences in motor plans of goal-directed movement only when sensory feedback could not be used due to temporal constraints. In addition, this cerebellar region (lobule VI) was the best predictor of performance in children, suggesting that the maturation of accurate predictive estimates, which have been associated with Purkinje cell activity in the cerebellar vermis (Laurens et al., 2013), drives bimanual coordination performance in this population. This result is consistent with previous findings showing that lobule VI is critical for motor tasks (i.e., sequence learning and visuomotor adaptation) and especially for spatial tasks (including interlimb coordination tasks (Beets et al., 2015; Debaere et al., 2003, 2004a,b; Goble et al., 2010; Santos Monteiro et al., 2017; Wenderoth et al., 2004, 2006). This result also supports previous findings based on smooth pursuit eye movements and split-belt walking, suggesting that the maturation of motor functions is determined by the developmental state of the cerebellum (Ego et al., 2016; Vasudevan et al., 2011). These results in children and older adults also support previous findings of the critical role of the cerebellum in bimanual coordination (Debaere et al., 2004a). Taken together, these results underscore the cerebellum's critical role in bimanual coordination performance in children and older adults, and they suggest that predictive models in the cerebellum are the key for the development and preservation of motor functions.

The complementary whole-cerebellum voxelwise analysis did not show any significant result, thereby failing to support the results of the linear mixed model ROI analysis and also failing to reveal additional cerebellar regions involved in bimanual coordination (such as the anterior lobe of the cerebellum as hypothesized). The nonsignificance of the voxelwise results may be related to the lower power and/or higher noise associated with this analysis as compared to the ROI analysis, which is based on linear mixed models and average intensities across voxels of the ROI.

\subsection{Other gray matter regions explaining bimanual coordination performance}

Our results also showed that higher gray matter intensity in the M1 was associated with higher bimanual coordination performance in older adults, supporting the results of previous bimanual coordination studies showing the effect of age on M1 integrity and structural connectivity. In a similar bimanual multifrequency tracking task, better performance was associated with better corpus callosum microstructural properties of the subregion connecting the M1 in older adults (Fujiyama et al., 2016; Serbruyns et al., 2015) and higher gray matter intensity in the M1 (van Ruitenbeek et al., 2017). Our results also revealed that the M1 mediates the effect of age on bimanual performance in older adults, suggesting for the first time that the effect of aging on bimanual performance may be indirect and explained by the adverse effect of aging on M1 gray matter structure. However, this mediation stems from correlational data and, as such, cannot imply causality but encourages future studies to further investigate this avenue.

Our results also revealed that gray matter intensity of the motor cingulate explains bimanual coordination performance in adults aged 40-60 years, consistent with previous fMRI studies of bimanual coordination showing age-related hyperactivity in the cingulate motor cortex (Goble et al., 2010) and gray matter decline in this region (van Ruitenbeek et al., 2017) during these tasks. Other studies have shown that the anterior cingulate seems to be particularly important for bimanual tasks by suppressing intrinsically favored coordination tendencies (Wenderoth et al., 2005).

Unlike the abovementioned regions, higher gray matter intensity in the S1 and premotor cortex were associated with lower bimanual coordination performance. Although unexpected, this result was consistent for the $\mathrm{S} 1$ across the 2 older groups. This could be explained by a stronger reliance on somatosensory feedback in older adults, which has been shown to result in poorer performance on motor tasks compared to predictive movement control (Boisgontier and Nougier, 2013). This result could also be specific to the task, as maximum reliance on visual information may have been the best task performance strategy in the present study, which would imply that the somatosensory feedback hampers performance.

Vigor signal originates in the basal ganglia (Dudman and Krakauer, 2016) and appears to control the gain of decisionrelated cells in the premotor cortex (Thura and Cisek, 2016). Administration of levodopa into the basal ganglia ameliorates deficits in movement vigor (Panigrahi et al., 2015). However, increased movement vigor can also result in premature responses in a choice reaction-time task (Economidou et al., 2012) and exaggerated postural adjustments (Boisgontier et al., 2017a). In line with these findings, higher gray matter intensity in the premotor cortex may result in lower thresholds to vigor signals and trigger movements that are more vigorous. Such increased vigor may result in premature or exaggerated adjustments of the movement trajectory, thereby increasing target deviation, that is, increasing errors in a bimanual coordination task.

\section{Conclusion}

The gray matter structure of cerebellar lobule VI appears to be critical for the control of bimanual movement at both ends of the age spectrum. One specific neural mechanism that could be associated with this age-related plasticity is predictive modeling, which is thought to take place in the cerebellum. Whether these findings obtained from a bimanual coordination task can be applied to a wider range of sensorimotor tasks remains to be determined.

\section{Disclosure statement}

The authors have no actual or potential conflicts of interest.

\section{Acknowledgements}

MPB and SPS are supported by the Research Foundation-Flanders (FWO; 1501018N; 1504015N; 1519916N; G0708.14; G089818N). SPS is supported by the KU Leuven Research Fund (C16/15/070) and Excellence of Science grant (EOS, 30446199, MEMODYN). The authors are thankful to Leen Serbruyns and René Clerckx for helping with data acquisition and analysis and JeanJacques Orban de Xivry for useful comments on the article.

Authors' contributions: study design: KC, RM, SPS; experimental conduct: KC and RM; imaging data analysis: MPB, PVR, IL; statistical analyses: MPB, BC, OR; article drafting: MPB; article editing and revision: MPB, BC, PvR, KC, IL, SS, RM, HZA, OR, and SPS.

\section{Appendix A. Supplementary data}

Supplementary data associated with this article can be found, in the online version, at https://doi.org/10.1016/j.neurobiolaging.2018. 01.016. 


\section{References}

Abrahamová, D., Hlavacka, F., 2008. Age-related changes of human balance during quiet stance. Physiol. Res. 57, 957-964.

Ainsworth, B.E., Haskell, W.L., Whitt, M.C., Irwin, M.L., Swartz, A.M., Strath, S.J., 2000. Compendium of physical activities: an update of activity codes and MET intensities. Med. Sci. Sports Exerc 32, S498-S504.

Andersen, B.B., Gundersen, H.J., Pakkenberg, B., 2003. Aging of the human cerebellum: a stereological study. J. Comp. Neurol. 466, 356-365.

Andersson, J.L.R., Jenkinson, M., Smith, S., 2007. Non-linear Registration, Aka Spatial Normalisation. FMRIB technical report TR07JA2 from. www.fmrib.ox.ac.uk/ analysis/techrep 2007.

Ashburner, J., 2007. A fast diffeomorphic image registration algorithm. Neuroimage 38, 95-113.

Ashburner, J., Friston, K.J., 2000. Voxel-based morphometry - the methods. Neuroimage 11, 805-821.

Baayen, R.H., Davidson, D.J., Bates, D.M., 2008. Mixed-effects modeling with crossed random effects for subjects and items. J. Mem. Lang. 59, 390-412.

Barr, D.J., Levy, R., Scheepers, C., Tily, H.J., 2013. Random effects structure for confirmatory hypothesis testing: keep it maximal. J. Mem. Lang. 68, 255-278.

Beets, I.A.M., Gooijers, J., Boisgontier, M.P., Pauwels, L., Coxon, J.P., Wittenberg, G., Swinnen, S.P., 2015. Reduced neural differentiation between feedback conditions after bimanual coordination training with and without augmented visual feedback. Cereb. Cortex 25, 1958-1969.

Bernard, J.A., Seidler, R.D., 2013a. Cerebellar contributions to visuomotor adaptation and motor sequence learning: an ALE meta-analysis. Front. Hum. Neurosci. 7,27.

Bernard, J.A., Seidler, R.D., 2013b. Relationships between regional cerebellar volume and sensorimotor and cognitive function in young and older adults. Cerebellum 12, 721-737.

Boisgontier, M.P., 2015. Motor aging results from cerebellar neuron death. Trends Neurosci. 38, 127-128.

Boisgontier, M.P., Beets, I.A.M., Duysens, J., Nieuwboer, A., Krampe, R.T. Swinnen, S.P. 2013. Age-related differences in attentional cost associated with postural dual tasks: increased recruitment of generic cognitive resources in older adults. Neurosci. Biobehav. Rev. 37, 1824-1837.

Boisgontier, M.P., Cheval, B., 2016. The anova to mixed model transition. Neurosci. Biobehav. Rev. 68, 1004-1005.

Boisgontier, M.P., Cheval, B., Chalavi, S., van Ruitenbeek, P., Leunissen, I., Levin, O., Nieuwboer, A., Swinnen, S.P., 2017a. Individual differences in brainstem and basal ganglia structure predict postural control and balance loss in young and older adults. Neurobiol. Aging 50, 47-59.

Boisgontier, M.P., Nougier, V., 2013. Ageing of internal models: from a continuous to an intermittent proprioceptive control of movement. Age 35, 1339-1355.

Boisgontier, M.P., Serbruyns, L., Swinnen, S.P., 2017b. Physical activity predicts performance in an unpracticed bimanual coordination task. Front. Psychol. 8, 249.

Boisgontier, M.P., Wittenberg, G.F., Fujiyama, H., Levin, O., Swinnen, S.P., 2014. Complexity of central processing in simple and choice multilimb reaction-time tasks. PLoS One 9, e90457.

Booth, M., 2000. Assessment of physical activity: an internationalperspective. Res. Q. Exerc. Sport 71, S114-S120.

Box, G.E.P., Cox, D.R., 1964. An analysis of transformations. J. R. Stat. Soc. Series B Stat. Methodol, 26, 211-252.

Brooks, S.V., Faulkner, J.A., 1994. Skeletal muscles weakness in old age: underlying mechanisms. Med. Sci. Sports Exerc. 26, 432-439.

Burton, A.W., 1987. The effect of number of movement components on response time in children. J. Hum. Mov. Stud. 13, 231-247.

Casamento-Moran, A., Chen, Y.T., Lodha, N., Yacoubi, B., Christou, E.A., 2017. Motor plan differs for young and older adults during similar movements. J. Neurophysiol. 117, 1483-1488.

Chalavi, S., Zivari Adab, H., Pauwels, L., Beets, I.A.M., van Ruitenbeek, P., Boisgontier, M.P., Santos Monteiro, T., Maes, C., Sunaert, S., Swinnen, S.P., 2018. Anatomy of subcortical structures predicts age-related differences in skill acquisition. Cereb. Cortex 28, 459-473.

Cohen, J., 1988. Statistical Power Analysis for the Behavioral Sciences, second ed. Erlbaum, Hillsdale, USA.

Corporaal, S.H.A., Gooijers, J., Chalavi, S., Cheval, B., Swinnen, S.P., Boisgontier, M.P. 2017. Neural predictors of motor control and impact of visuo-proprioceptive information in youth. Hum. Brain Mapp. 38, 5628-5647.

Coxon, J.P., Goble, D.J., Van Impe, A., De Vos, J., Wenderoth, N., Swinnen, S.P., 2010. Reduced basal ganglia function when elderly switch between coordinated movement patterns. Cereb. Cortex 20, 2368-2379.

Craig, C.L., Marshall, A.L., Sjostrom, M., Bauman, A., Booth, M.L., Ainsworth, B.E., Pratt, M., Ekelund, U., Yngve, A., Sallis, J.F., Oja, P., 2003. International physical activity Questionnaire: 12-country reliability and validity. Med. Sci. Sports Exerc. 35, 1381-1395.

Davidian, M., Giltinan, D.M., 1995. Nonlinear Models for Repeated Measurement Data. Chapman \& Hall, London, UK.

Debaere, F., Wenderoth, N., Sunaert, S., Van Hecke, P., Swinnen, S.P., 2003. Internal vs external generation of movements: differential neural pathways involved in bimanual coordination performed in the presence or absence of augmented visual feedback. Neuroimage 19, 764-776.

Debaere, F., Wenderoth, N., Sunaert, S., Van Hecke, P., Swinnen, S.P., 2004a. Cerebellar and premotor function in bimanual coordination: parametric neural responses to spatiotemporal complexity and cycling frequency. Neuroimage 21, 1416-1427.

Debaere, F., Wenderoth, N., Sunaert, S., Van Hecke, P., Swinnen, S.P., 2004b. Changes in brain activation during the acquisition of a new bimanual coordination task Neuropsychologia 42, 855-867.

Deng, H.B., Macfarlane, D.J., Thomas, G.N., Lao, X.Q., Jiang, C.Q., Cheng, K.K. Lam, T.H., 2008. Reliability and validity of the IPAQ-Chinese: the Guangzhou Biobank cohort study. Med. Sci. Sports Exerc. 40, 303-307.

Diedrichsen, J., 2006. A spatially unbiased atlas template of the human cerebellum. Neuroimage 33, 127-138.

Diedrichsen, J., Balsters, J.H., Flavell, J., Cussans, E., Ramnani, N., 2009. A probabilistic MR atlas of the human cerebellum. Neuroimage 46, 39-46.

Donchin, O., Gribova, A., Steinberg, O., Bergman, H., Vaadia, E., 1998. Primary motor cortex is involved in bimanual coordination. Nature 395, 274-278.

Donchin, O., Rabe, K., Diedrichsen, J., Lally, N., Schoch, B., Gizewski, E.R. Timmann, D., 2012. Cerebellar regions involved in adaptation to force field and visuomotor perturbation. J. Neurophysiol. 107, 134-147.

Douaud, G., Smith, S., Jenkinson, M., Behrens, T., Johansen-Berg, H., Vickers, J., James, S., Voets, N., Watkins, K., Matthews, P.M., James, A., 2007. Anatomically related grey and white matter abnormalities in adolescent-onset schizophrenia. Brain 130, 2375-2386.

Dudman, J.T., Krakauer, J.W., 2016. The basal ganglia: from motor commands to the control of vigor. Curr. Opin. Neurobiol. 37, 158-166.

Economidou, D., Theobald, D.E., Robbins, T.W., Everitt, B.J., Dalley, J.W., 2012 Norepinephrine and dopamine modulate impulsivity on the five-choice seria reaction time task through opponent actions in the shell and core sub-regions of the nucleus accumbens. Neuropsychopharmacology 37, 2057-2066.

Ego, C., Yüksel, D., Orban de Xivry, J.J., Lefèvres, P., 2016. Development of interna models and predictive abilities for visual tracking during childhood. J. Neurophysiol. 115, 301-309.

Eklund, A., Nichols, T.E., Knutsson, H., 2016. Cluster failure: why fMRI inferences for spatial extent have inflated false-positive rates. Proc. Natl. Acad. Sci. U. S. A. 113 7900-7905.

Faraway, J.J., 2006. Extending the Linear Model with R: Generalized Linear, Mixed Effects and Nonparametric Regression Models. Chapman \& Hall/CRC, Boca Raton, FL.

Fjell, A.M., Walhovd, K.B., Westlye, L.T., Østby, Y., Tamnes, C.K., Jernigan, T.L., Gamst, A., Dale, A.M., 2010. When does brain aging accelerate? Dangers of quadratic fits in cross-sectional studies. Neuroimage 50, 1376-1383.

Fjell, A.M., Westlye, L.T., Grydeland, H., Amlien, I., Espeseth, T., Reinvang, I., Raz, N. Holland, D., Dale, A.M., Walhovd, K.B. Alzheimer Disease Neuroimaging Initiative, 2013. Critical ages in the life course of the adult brain: nonlinear subcortical aging. Neurobiol. Aging 34, 2239-2247.

Fujiyama, H., Van Soom, J., Rens, G., Gooijers, J., Leunissen, I., Levin, O., Swinnen, S.P. 2016. Age-related changes in frontal network structural and functional connectivity in relation to bimanual movement control. J. Neurosci. 36, 1808-1822.

Goble, D.J., Coxon, J.P., Van Impe, A., De Vos, J., Wenderoth, N., Swinnen, S.P., 2010 The neural control of bimanual movements in the elderly: brain regions exhibiting age-related increases in activity, frequency-induced neural modulation, and task-specific compensatory recruitment. Hum. Brain Mapp. 31 1281-1295.

Good, C.D., Johnsrude, I.S., Ashburner, J., Henson, R.N., Friston, K.J., Frackowiak, R.S., 2001. A voxel-based morphometric study of ageing in 465 normal adult human brains. Neuroimage 14, 21-36.

Grady, C., 2012. The cognitive neuroscience of ageing. Nat. Rev. Neurosci. 13, 491-505.

Grodd, W., Hülsmann, E., Lotze, M., Wildgruber, D., Erb, M., 2001. Sensorimotormapping of the human cerebellum: fMRI evidence of somatotopic organization. Hum. Brain Mapp. 13, 55-73.

Hair Jr., J.F., Anderson, R.E., Tatham, R.L., Black, W.C., 1995. Multivariate Data Analysis, third ed. Macmillan, New York.

Hall, T.C., Miller, A.K.H., Corsellis, J.A.N., 1975. Variations in the human Purkinje cel population according to sex and age. Neuropath. Appl. Neurobiol. 1, 267-292.

Hastie, T.J., Tibshirani, R.J., Friedman, J.H., 2008. The Elements of Statistical Learning: Data Mining, Inference, and Prediction, second ed. Springer, USA.

Hekman, K.E., Gomez, C.M., 2015. The autosomal dominant spinocerebellar ataxias: emerging mechanistic themes suggest pervasive Purkinje cell vulnerability J. Neurol. Neurosurg. Psychiatry 86, 554-561.

Helsen, W.F., Van Halewyck, F., Levin, O., Boisgontier, M.P., Lavrysen, A., Elliott, D., 2016. Manual aiming in healthy aging: does proprioceptive acuity make the difference? Age 38, 45.

Huang, C.C. Sugino, K. Shima, Y., Guo, C., Bai, S., Mensh, B.D., Nelson, S.B. Hantman, A.W., 2013. Convergence of pontine and proprioceptive streams onto multimodal cerebellar granule cells. Elife 2, e00400.

Judd, C.M., Westfall, J., Kenny, D.A., 2012. Treating stimuli as a random factor in social psychology: a new and comprehensive solution to a pervasive but largely ignored problem. J. Pers. Soc. Psychol. 103, 54-69.

Kallman, D.A., Plato, C.C., Tobin, J.D., 1990. The role of muscle loss in the age-related decline of grip strength: cross-sectional and longitudinal perspectives. J. Gerontol, 45, M82-M88.

Kararizou, E., Manta, P., Kalfakis, N., Vassilopoulos, D., 2005. Morphometric study of the human muscle spindle. Anal. Quant. Cytol. Histol. 27, 1-4.

Katz, S., Downs, T.D., Cash, H.R., Grotz, R.C., 1970. Progress in development of the index of ADL. Gerontologist 10, 20-30. 
Kelly, R., Strick, P., 2003. Cerebellar loops with motor cortex and prefrontal cortex. J. Neurosci. 23, 8432-8444.

Laurens, J., Meng, H., Angelaki, D.E., 2013. Computation of linear acceleration through an internal model in the macaque cerebellum. Nat. Neurosci. 16, $1701-1708$.

Leinen, P., Vieluf, S., Kennedy, D., Aschersleben, G., Shea, C.H., Panzer, S., 2016. Life span changes: performing a continuous 1:2 bimanual coordination task. Hum. Mov. Sci. 46, 209-220.

Luft, A.R., Skalej, M., Schulz, J.B., Welte, D., Kolb, R., Bürk, K., Klockgether, T., Voight, K., 1999. Patterns of age-related shrinkage in cerebellum and brainstem observed in vivo using three-dimensional MRI volumetry. Cereb. Cortex 9, 712-721.

Luke, S.G., 2017. Evaluating significance in linear mixed-effects models in R. Behav. Res. Methods 49, 1494-1502.

Mäder, U., Martin, B.W., Schutz, Y., Marti, B., 2006. Validity of four short physical activity questionnaires in middle-aged persons. Med. Sci. Sports Exerc 38, 1255-1266.

Maes, C., Gooijers, J., Orban de Xivry, J.J., Swinnen, S.P., Boisgontier, M.P., 2017. Two hands, one brain, and aging. Neurosci. Biobehav. Rev. 75, 234-256.

Marion, S.D., Kilian, S.C., Naramor, T.L., Brown, W.S., 2003. Normal development of bimanual coordination: visuomotor and interhemispheric contributions. Dev. Neuropsychol. 23, 399-421.

Moes, P., Jeeves, M.A., Cook, K., 1995. Bimanual coordination with aging: implications for interhemispheric transfer. Dev. Neuropsychol. 11, 23-40.

Muetzel, R.L., Collins, P.F., Mueller, B.A., Schissel, A.M., Lim, K.O., Luciana, M., 2008. The development of corpus callosum microstructure and associations with bimanual task performance in healthy adolescents. Neuroimage 39, 1918-1925.

Nair, K.S., 2005. Aging muscle. Am. J. Clin. Nutr. 81, 953-963.

Nichols, T., Brett, M., Andersson, J., Wager, T., Poline, J.B., 2005. Valid conjunction inference with the minimum statistic. Neuroimage 25, 653-660.

Oldfield, R.C., 1971. The assessment and analysis of handedness: the Edinburgh inventory. Neuropsychologia 9, 97-113.

Osborne, J.W., 2010. Improving your data transformations: applying the Box-Cox transformation. Pract. Assess. Res. Eval 15, 1-9.

Panigrahi, B., Martin, K.A., Li, Y., Graves, A.R., Vollmer, A., Olson, L., Mensh, B.D., Karpova, A.Y., Dudman, J.T., 2015. Dopamine is required for the neural representation and control of movement vigor. Cell 162, 1418-1430.

Papathanasiou, G., Georgoudis, G., Georgakopoulos, D., Katsouras, C., Kalfakakou, V., Evangelou, A., 2010. Criterion-related validity of the short International Physical Activity Questionnaire against exercise capacity in young adults. Eur. J. Cardiovasc. Prev. Rehabil. 17, 380-386.

Peters, A., Kemper, T., 2012. A review of the structural alterations in the cerebral hemispheres of the aging rhesus monkey. Neurobiol. Aging 33, 2357-2372.

Puttemans, V., Wenderoth, N., Swinnen, S.P., 2005. Changes in brain activation during the acquisition of a multifrequency bimanual coordination task: from the cognitive stage to advanced levels of automaticity. J. Neurosci. 25, 4270-4278.

Rabe, K., Livne, O., Gizewski, E.R., Aurich, V., Beck, A., Timmann, D., Donchin, O., 2009. Adaptation to visuomotor rotation and force field perturbation is correlated to different brain areas in patients with cerebellar degeneration. J. Neurophysiol. 101, 1961-1971.

Raz, N., Gunning-Dixon, F., Head, D., Williamson, A., Acker, J.D., 2001. Age and sex differences in the cerebellum and the ventral pons: a prospective MR study of healthy adults. Am. J. Neuroradiol. 22, 1161-1167.

Reuter-Lorenz, P.A., Cappell, K.A., 2008. Neurocognitive aging and the compensation hypothesis. Curr. Dir. Psychol. Sci. 17, 177-182.

Ridgway, G., Barnes, J., Pepple, T., Fox, N., 2011. Estimation of total intracranial volume; a comparison of methods. Alzheimers Dement. 7, S62-S63.

Rinehart, J.K., Singleton, R.D., Adair, J.C., Sadek, J.R., Haaland, K.Y., 2009. Arm use after left or right hemiparesis is influenced by hand preference. Stroke 40, 545-550.

Sadato, N., Yonekura, Y., Waki, A., Yamada, H., Ishii, Y., 1997. Role of the supplementary motor area and the right premotor cortex in the coordination of bimanual finger movements. J. Neurosci. 17, 9667-9674.

Santos Monteiro, T., Beets, I.A.M., Boisgontier, M.P., Gooijers, J., Pauwels, L., Chalavi, S., King, B., Albouy, G., Swinnen, S.P., 2017. Relative cortico-subcortical shift in brain activity but preserved training-induced neural modulation in older adults during bimanual motor learning. Neurobiol. Aging 58, 54-67.

Scheeres, K., Knoop, H., van der Meer, J., Bleijenberg, G., 2009. Clinical assessment of the physical activity pattern of chronic fatigue syndrome patients: a validation of three methods. Health Qual. Life Outcomes 7, 29.

Schmahmann, J.D., Doyon, J., Toga, A., Petrides, M., Evans, A.C., 2000. MRI Atlas of the Human Cerebellum. Academic Press, San Diego, USA.

Schneider-Garces, N.J., Gordon, B.A., Brumback-Peltz, C.R., Shin, E., Lee, Y., Sutton, B.P., Maclin, E.L., Gratton, G., Fabiani, M., 2010. Span, CRUNCH, and beyond: working memory capacity and the aging brain. J. Cogn. Neurosci. 22, 655-669.

Serbruyns, L., Gooijers, J., Caeyenberghs, K., Meesen, R.L., Cuypers, K., Sisti, H.M., Leemans, A., Swinnen, S.P., 2015. Bimanual motor deficits in older adults predicted by diffusion tensor imaging metrics of corpus callosum subregions. Brain Struct. Funct. 220, 273-290.
Sexton, C.E., Walhovd, K.B., Storsve, A.B., Tamnes, C.K., Westlye, L.T., JohansenBerg, H., Fjell, A.M., 2014. Accelerated changes in white matter microstructure during aging: a longitudinal diffusion tensor imaging study. J. Neurosci. 34 15425-15436.

Singer, J.D., Willett, J.B., 2003. Applied Longitudinal Data Analysis: Modeling Change and Event Occurrence. Oxford university press, USA.

Smith, C.D., Umberger, G.H., Manning, E.L., Slevin, J.T., Wekstein, D.R., Schmitt, F.A. Markesbery, W.R., Zhang, Z., Gerhardt, G.A., Kryscio, R.J., Gash, D.M., 1999 Critical decline in fine motor hand movements in human aging. Neurology 53 $1458-1461$.

Smith, S.M., Jenkinson, M., Woolrich, M.W., Beckmann, C.F., Behrens, T.E.J., JohansenBerg, H., Bannister, P.R., De Luca, M., Drobnjak, I., Flitney, D.E., Niazy, R. Saunders, J., Vickers, J., Zhang, Y., De Stefano, N., Brady, J.M., Matthews, P.M., 2004. Advances in functional and structural MR image analysis and implementation as FSL. Neuroimage 23, S208-S219.

Snider, R., Eldred, E., 1951. Electro-anatomical studies on cerebrocerebellar connections in the cat. J. Comp. Neurol. 95, 1-16.

Sobel, H., 1966. When does human aging start? Gerontologist 6, 17-22.

Stoodley, C.J., Schmahmann, J.D., 2010. Evidence for topographic organization in the cerebellum of motor control versus cognitive and affective processing. Cortex 46, 831-844.

Stoodley, C.J., Schmahmann, J.D., 2009. Functional topography in the human cerebellum: a meta-analysis of neuroimaging studies. Neuroimage 44, 489-501.

Stoodley, C.J., Valera, E.M., Schmahmann, J.D., 2012. Functional topography of the cerebellum for motor and cognitive tasks: an fMRI study. Neuroimage 59 1560-1570.

Swinnen, S.P., 2002. Intermanual coordination: from behavioural principles to neural-network interactions. Nat. Rev. Neurosci. 3, 348-359.

Swinnen, S.P., Wenderoth, N., 2004. Two hands, one brain: cognitive neuroscience of bimanual skill. Trends Cogn. Sci. 8, 18-25.

Thura, D., Cisek, P., 2016. Modulation of premotor and primary motor cortical activity during volitional adjustments of speed-accuracy trade-offs. J. Neurosci. 36, 938-956.

Tiemeier, H., Lenroot, R.K., Greenstein, D.K., Tran, L., Pierson, R., Giedd, J.N., 2010 Cerebellum development during childhood and adolescence: a longitudinal morphometric MRI study. Neuroimage 49, 63-70.

Tracy, J.I., Faro, S.S., Mohammed, F.B., Pinus, A.B., Madi, S.M., Laskas, J.W., 2001 Cerebellar mediation of the complexity of bimanual compared to unimanual movements. Neurology 57, 1862-1869.

van Ruitenbeek, P., Serbruyns, L., Solesio-Jofre, E., Meesen, R., Cuypers, K. Swinnen, S.P., 2017. Cortical grey matter content is associated with both age and bimanual performance, but is not observed to mediate age-related behavioural decline. Brain Struct. Funct. 222, 437-448.

Vasudevan, E.V., Torres-Oviedo, G., Morton, S.M., Yang, J.F., Bastian, A.J., 2011 Younger is not always better: development of locomotor adaptation from childhood to adulthood. J. Neurosci. 31, 3055-3065.

Vega-Gonzalez, A., Granat, M.H., 2005. Continuous monitoring of upper-limb activity in a free-living environment. Arch. Phys. Med. Rehabil. 86, 541-548.

Verhaeghen, P., Steitz, D.W., Sliwinski, M.J., Cerella, J., 2003. Aging and dual-task performance: a meta-analysis. Psychol. Aging 18, 443-460.

Walhovd, K.B., Fjell, A.M., Reinvang, I., Lundervold, A., Dale, A.M., Eilertsen, D.E., Quinn, B.T., Salat, D., Makris, N., Fischl, B., 2005. Effects of age on volumes of cortex, white matter and subcortical structures. Neurobiol. Aging 26, 1261-1270.

Wang, V.Y., Zoghbi, H.Y., 2001. Genetic regulation of cerebellar development. Nat. Rev. Neurosci. 2, 484-491.

Wang, X., Michaelis, E.K., 2010. Selective neuronal vulnerability to oxidative stress in the brain. Front. Aging Neurosci. 2, 12.

Wenderoth, N., Debaere, F., Sunaert, S., Swinnen, S.P., 2005. The role of anterior cingulate cortex and precuneus in the coordination of motor behaviour. Eur. J. Neurosci. 22, 235-246.

Wenderoth, N., Debaere, F., Sunaert, S., van Hecke, P., Swinnen, S.P., 2004. Parietopremotor areas mediate directional interference during bimanual movements. Cereb. Cortex 14, 1153-1163.

Wenderoth, N., Toni, I., Bedeleem, S., Debaere, F., Swinnen, S.P., 2006. Information processing in human parieto-frontal circuits during goal-directed bimanual movements. Neuroimage 31, 264-278.

Williams, V., Hayes, J.P., Forman, D.E., Salat, D.H., Sperling, R.A., Verfaellie, M. Hayes, S.M., 2017. Cardiorespiratory fitness is differentially associated with cortical thickness in young and older adults. Neuroimage 146, 1084-1092.

Wolpert, D.M., Miall, R.C., Kawato, M., 1998. Internal models in the cerebellum. Trends Cogn. Sci. 2, 338-347.

Wood, S., 2006. Generalized additive models: an introduction with R. CRC Press, USA.

Yan, J.H., Thomas, J.R., Stelmach, G.E., Thomas, K.T., 2000. Developmental features of rapid aiming arm movements across the lifespan. J. Mot. Behav. 32, 121-140.

Zuur, A., Ieno, E.N., Walker, N., Saveliev, A.A., Smith, G.M., 2009. Mixed Effects Models and Extensions in Ecology with R. Springer, New York, NY. 